Journal of World's

Poultry Research

\title{
Isolation of Newcastle Disease Virus from Wild Migratory Birds in Egypt
}

\author{
Mohammed Hasan Mohammed ${ }^{1}$, Ahmed Kandeil ${ }^{2}$, Maha Alkhazindar ${ }^{1}$, \\ Elsayed Tarek AbdElSalam ${ }^{1}$ and Mohamed Ahmed $\mathrm{Ali}^{2} *$ \\ ${ }^{1}$ Department of Botany and Microbiology, Faculty of Science, Cairo University, Gamaa Street, Giza 12613, Egypt \\ ${ }^{2}$ Center of Scientific Excellence for Influenza Virus, Environmental Research Division, National Research Centre, Giza 12622, Egypt \\ ${ }^{*}$ Corresponding author's Email: mohamedahmedali2004@yahoo.com; ORCID: 0000-0002-5615-3212
}

Received: 07 Aug. 2020

Accepted: 22 Sept. 2020

\begin{abstract}
Surveillance studies for Newcastle disease virus (NDV) are critical to monitor the potential spreading of these viruses among wild birds as well as domestic poultry. This study was conducted to determine the incidence of NDV in wild birds in Egypt in 2016. Out of 159 collected samples from eight different species of wild birds, six (3.77\%) samples were positive for paramyxoviruses by semi-nested RT-PCR assay based on the RNA-dependent RNA polymerase gene. Of six positive samples, four NDVs were successfully isolated in 11-day-old specific-pathogen-free embryonated hens' eggs. Partial sequences of the fusion gene of the four isolates were amplified using RT-PCR. Phylogenetic analysis of partial sequences of RNA-dependent RNA polymerase gene and fusion genes indicated that the detected NDV viruses in wild birds in Egypt are related to class I NDVs strains. Four Egyptian NDV isolates from wild birds exhibited sequence motif of ${ }^{111} \mathrm{GERQER} \downarrow L V \mathrm{G}^{119}$ at the cleavage site as lentogenic virus in wild birds. Continuous active surveillance may help better monitoring of NDVs circulating in wild birds before newly emerging viruses in domestic poultry.
\end{abstract}

Keywords: Egypt, Fusion protein, Newcastle disease virus, Wild birds

\section{INTRODUCTION}

Newcastle Disease Virus (NDV) is an enveloped RNA virus with a negative single-stranded, non-segmented genome of approximately $15 \mathrm{~kb}$ in length which encodes nucleocapsid protein (NP), fusion protein (F), hemagglutinin-neuraminidase protein $(\mathrm{HN})$, matrix protein (M), polymerase protein (L) and phosphoprotein (P) (Swayne and King, 2003). The NDV was reported first time in Newcastle, England in 1926 and was responsible for the four panzootic in the UK (Alexander, et al., 1992). NDV is a member of the genus Avulavirus, which belongs to the family Paramyxoviridae (ICTV, 2013). NDVs have been classified into two main classes I and II. Class I of NDV comprises only one genotype that has been detected and isolated from wild birds whereas class II includes 18 genotypes that are circulating in domestic and wild birds (Xiao et al., 2012). NDVs can infect at least 240 different domestic and wild bird species. Based on virulence, NDVs are classified into three strains: velogenic strains that cause killer hemorrhagic, neurological disorders, and respiratory illness; mesogenic strains causing infection of respiratory system with limited mortality; and lentogenic strains that cause enteric diseases and not severe respiratory infection (Dortmans et al., 2011).

In Egypt, there have been continuous reports associated with Newcastle disease outbreaks among domestic poultry, which have affected the economy of poultry industries (Shakal et al., 2020). Based on NDV genotypic characterization, genotype II, VI, and VII of class II have been identified in domestic poultry in Egypt (Mohamed et al., 2009; Mohamed et al., 2011; Saad et al., 2017).

The northern coast of Egypt serves as a stopover for migratory birds during the annual migration of birds from Asia and Europe to Africa and vice versa. Accordingly, these migratory birds play an essential role in the transmission of pathogens throughout their migration routes (Alexander, 2007). In addition to migratory birds, Egypt has several species of resident wild birds that live in 
close contact with domestic poultry as well as migratory wild birds and might play a role in the spread of newly emerging viruses.

Despite the potential threat posed by wild birds in the evolution of NDV, there is limited information about the genetic profile of NDVs circulating in wild birds in Egypt. Herein, the study detected and characterized the circulating NDVs among wildlife in Egypt.

\section{MATERIAL AND METHODS}

\section{Ethical approval}

Sampling from birds was approved by the ethical committee of the National Research Centre, Cairo, Egypt (registration number: 16247). All international, national, and institutional regulations on sampling from wild birds were followed.

\section{Samples collection}

From October to December 2016, a total of 159 cloacal samples taken from wild birds were individually collected from live bird markets of three northern coastal cities of Egypt [Damietta $(n=102)$, Port Said $(n=33)$, and Matruh $(\mathrm{n}=24)]$. The birds sampled included northern shoveler $(n=76)$, pintail $(n=39)$, laughing dove $(n=6)$, teal $(\mathrm{n}=31)$, wigeon $(\mathrm{n}=2)$, moorhen $(\mathrm{n}=1)$, mallard $(\mathrm{n}=1)$ and coot $(n=3)$. The cloacal swabs were collected in $2 \mathrm{ml}$ cryovials containing viral transport medium. Then the samples were transmitted to the laboratory in icebox to keep the temperature of the samples within the viral survival range. The collected samples were kept at $-80{ }^{\circ} \mathrm{C}$ for further analysis.

\section{Detection of paramyxoviruses in wild birds}

A volume of $140 \mu \mathrm{l}$ of each collected sample was subjected to viral RNA extraction using the QIAamp Virus RNA Mini Kit (Qiagen, Germany). Extracted viral RNA from each collected sample was subjected to cDNA synthesis using RevertAid First Strand cDNA Synthesis Kit (Thermo Scientific, USA). Detection of paramyxoviruses in all collected samples was based on semi-nested PCR targeting the RNA-dependent RNA polymerase (RdRp) gene (Tong et al., 2008). For the first round of semi-nested PCR for detection of paramyxoviruses in wild birds, $2 \mu$ l of each cDNA was mixed with $23 \mu \mathrm{l}$ of $12.5 \mu \mathrm{l}$ Green GoTaq master mix (Promega, USA), $1 \mu 1$ of forward primer (PAR-F1, 10 $\mathrm{pmol} / \mu \mathrm{l})$ (5'- GAAGGITATTGTCAIAARNTNTGGAC$\left.3^{\prime}\right), 1 \mu \mathrm{l}$ of reverse primer (PAR-R, $\left.10 \mathrm{pmol} / \mu \mathrm{l}\right)\left(5^{\prime}-\right.$ GCTGAAGTTACIGGITCICCDATRTTNC-3') and $8.5 \mu 1$ of RNase free water (Promega, USA) (Tong et al., 2008). After an initial incubation at $95{ }^{\circ} \mathrm{C}$ for 1 minute, 40 cycles of amplification were carried out consisting of denaturation at $95{ }^{\circ} \mathrm{C}$ for 1 minute, annealing at $48{ }^{\circ} \mathrm{C}$ for 1 minute, extension at $72{ }^{\circ} \mathrm{C}$ for 1 minute and terminated with a final extension of $72{ }^{\circ} \mathrm{C}$ for 7 minutes. The second round of semi-nested PCR was carried out by mixing of $12.5 \mu \mathrm{l}$ Green GoTaq master mix (Promega, USA), 10 pmol forward (PAR-F2) primer (5'GTTGCTTCAATGGTTCARGGNGAYAA-3'), 10 pmol reverse primer (PAR-R same reverse primer as round 1) and $8.5 \mu \mathrm{l}$ RNase free water. The thermal cycling condition for the second round was the same as the first round. PCR products were analyzed by standard agarose gel electrophoresis. The final $561 \mathrm{bp}$ PCR product was gel purified by Gel extraction kit (Qiagen, Germany) then sequenced using the primers of the second round of PCR at the Macrogen sequencing facility (Macrogen, South Korea).

\section{Newcastle disease virus isolation and amplification of partial $F$ gene and phylogenetic analysis}

All positive samples for paramyxoviruses were individually inoculated in the allantoic cavities of 11-dayold specific-pathogen-free (SPF) embryonated hens' eggs (Kom Oshem, Egypt) and incubated for three days. A volume of $50 \mu \mathrm{l}$ of harvested allantoic fluid was individually tested for hemagglutinating activity using $0.5 \%$ chicken red blood cells. The positive samples were subjected to viral RNA extraction using QIAamp Viral Mini Kit (Qiagen, Germany) according to the manufacturer's protocol. RT-PCR amplification of partial F gene was carried out in a $25 \mu \mathrm{l}$ which consist of $10 \mathrm{pmol}$ each of the forward NDV-F primer: 5'GGAGGATGTTGG CAGCATT-3' and reverse NDV-F primer: 5'-GTCAACATATACACCTCATC-3'(Pang et al., 2002). PCR reaction was carried out using Phusion master mix (Thermo Scientific, USA) according to the manufacturer's instructions. The final $320 \mathrm{bp} \mathrm{PCR} \mathrm{product}$ was gel purified by PCR purification kit (Qiagen, Germany) and sequenced with forward and reverse NDV$\mathrm{F}$ primers at the Macrogen sequencing facility (Macrogen, South Korea). Sequence alignment was performed using the BioEdit 7.0 software. The phylogenetic trees of RdRp and $\mathrm{F}$ genes were elaborated using the MEGA7 program by applying the neighbor-joining method with Kimura's two-parameter distance model and 1000 bootstrap replicates. Also, maximum-likelihood analysis for NDVs was performed using the MEGA7 program. All 
representative sequences from class I and genotypes (I to XVIII) of class II were obtained from GenBank as previously described by Dimitrov et al. (2016) and used to construct the phylogenetic trees for RdRp and $\mathrm{F}$ genes to identify the newly characterized NDVs in Egypt. Alignment of the deduced amino acid sequences of the $\mathrm{F}$ gene of NDVs isolated from wild birds in Egypt compared with representative class I and class II NDV strains was analyzed using BioEdit 7.0 software.

\section{RESULTS AND DISCUSSION}

In Egypt, Newcastle disease has been identified as a major cause of setbacks in the poultry industry. While there are no reports describing the incidence and pathotyping of NDVs in wild birds in Egypt, this study investigated the prevalence and diversity of NDVs circulating in wild birds in live bird markets in different cities of Egypt.

Out of 159 collected samples from eight different species of wild birds, $6(3.77 \%)$ samples were tested positive for paramyxoviruses. According to the location of collection, five $(4.90 \%)$ samples from Damietta, and one $(4.16 \%)$ sample from Matruh were positive for paramyxoviruses. No positive sample was detected in Port Said. According to the species of wild birds from which the samples were collected, five $(3.35 \%)$ positive samples were detected from the Anseriformes (2 from pintail and 3 from northern shoveler) and one (16.66\%) from Columbiformes (laughing dove). No positive sample was detected from coot, mallard, moorhen, teal, and wigeon.

Among six positive samples that were inoculated in SPF eggs, four samples were positive by hemagglutination assay. Positive samples were confirmed as NDV by RTPCR targeting the RdRp gene. Based on the application of RT-PCR targeting the F gene for NDV isolates, the results revealed $320 \mathrm{bp}$ PCR amplicons.

Huge data sets of NDVs sequences from different regions around the world were used to determine the pathotyping and origin of newly characterized viruses. Phylogenetic trees were constructed using partial sequences from the RdRp and F genes. Representative sequences from class I and genotypes (I to XVIII) of class II were used to build the general trees to identify the newly studied isolates from Egypt. Phylogenetic analysis showed that the isolated viruses during the current study were clustered and closely related to class I NDVs (Figures 1 and 2).
Following the BLAST analysis, the NDVs isolated in this study revealed about $97 \%$ similarity to the NDV strains JX07 and DE-R49/99 isolates based on the nucleotide identities.

The amino acid sequences of the $\mathrm{F}$ protein proteolytic cleavage site motifs $\left({ }^{111}\right.$ GERQER $\left.\downarrow L V G^{119}\right)$ were identical in the entire isolated NDV strains detected in different wild birds in Egypt (Figure 3). As a result of amino acids present in the cleavage site of $\mathrm{F}$ protein, which considers as a fingerprint for NDV pathogenicity, all Egyptian NDV strains detected in wild birds had lentogenic motif at the cleavage site. While the cleavage sites of velogenic and mesogenic strains (R/K-R-Q-R/K$\mathrm{R} \downarrow \mathrm{F}$ ) were not detected in the obtained sequences (Collins et al., 1993; Wang et al., 2017).

These results are in agreement with several previous studies detecting lentogenic NDVs in wild birds in several countries (Huovilainen et al., 2001; Kim et al., 2007; Jindal et al., 2009). The Egyptian NDVs isolated in this study do not appear to be phylogenetically related to live vaccines used in Egypt such as Lasota, indicating that the source of these viruses is not related to the shedding of the used vaccine strains. Although class I of NDVs was detected in domestic poultry in previous studies (Fan et al., 2015; Dimitrov et al., 2016), it was not wildly circulated like class II and caused effective losses in poultry industries. A previous study detected a virulent strain of class I of NDV during an outbreak recorded in Ireland in 1990 (Alexander et al., 1992).

Further virological and epidemiological studies from a broader host range are needed to determine the pathogenicity and host range of the circulating paramyxoviruses. However, virulent and mesogenic strains of NDVs were not detected in the current study, the presence of them cannot be excluded due to the nature of migration of wild birds across continents. Thus, continuous surveillance for NDV in wild birds is essential for a better understanding of its epidemiology.

In conclusion, this study characterized NDVs circulating in wild birds in Egypt. The close phylogenetic relationship between circulating NDV strains in wild birds and previously detected viruses of class I confirms the role of wild birds in the possibility of cross-species transmission among different hosts. The findings suggest the need for continuous systematic surveillance in wild birds. 

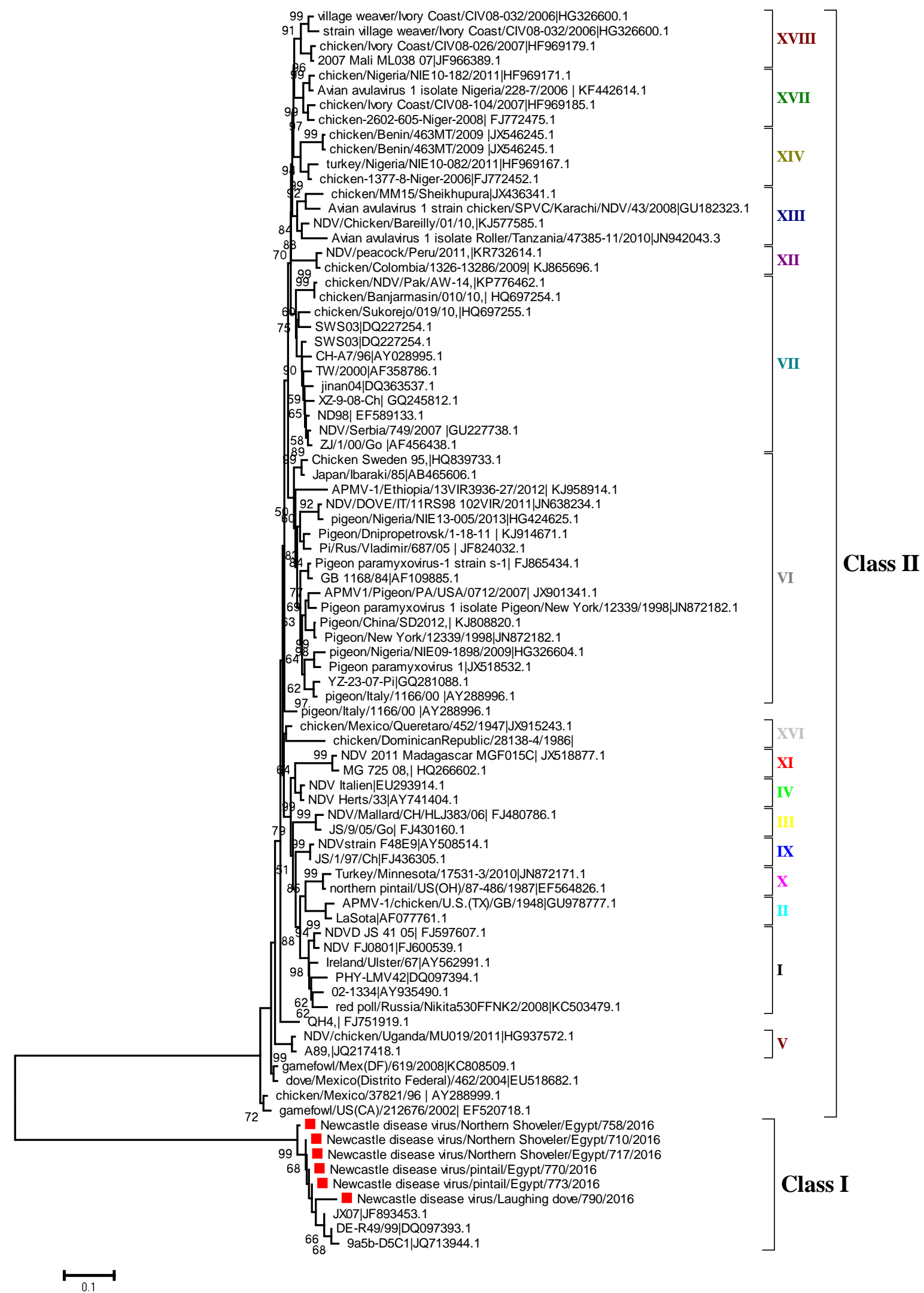

Figure 1. Neighbor-joining phylogenetic tree based on RNA-dependent RNA polymerase (RdRp) gene of Newcastle disease virus isolates from wild birds in Egypt. The wild bird isolates sequenced in the present study are marked with red squares. 


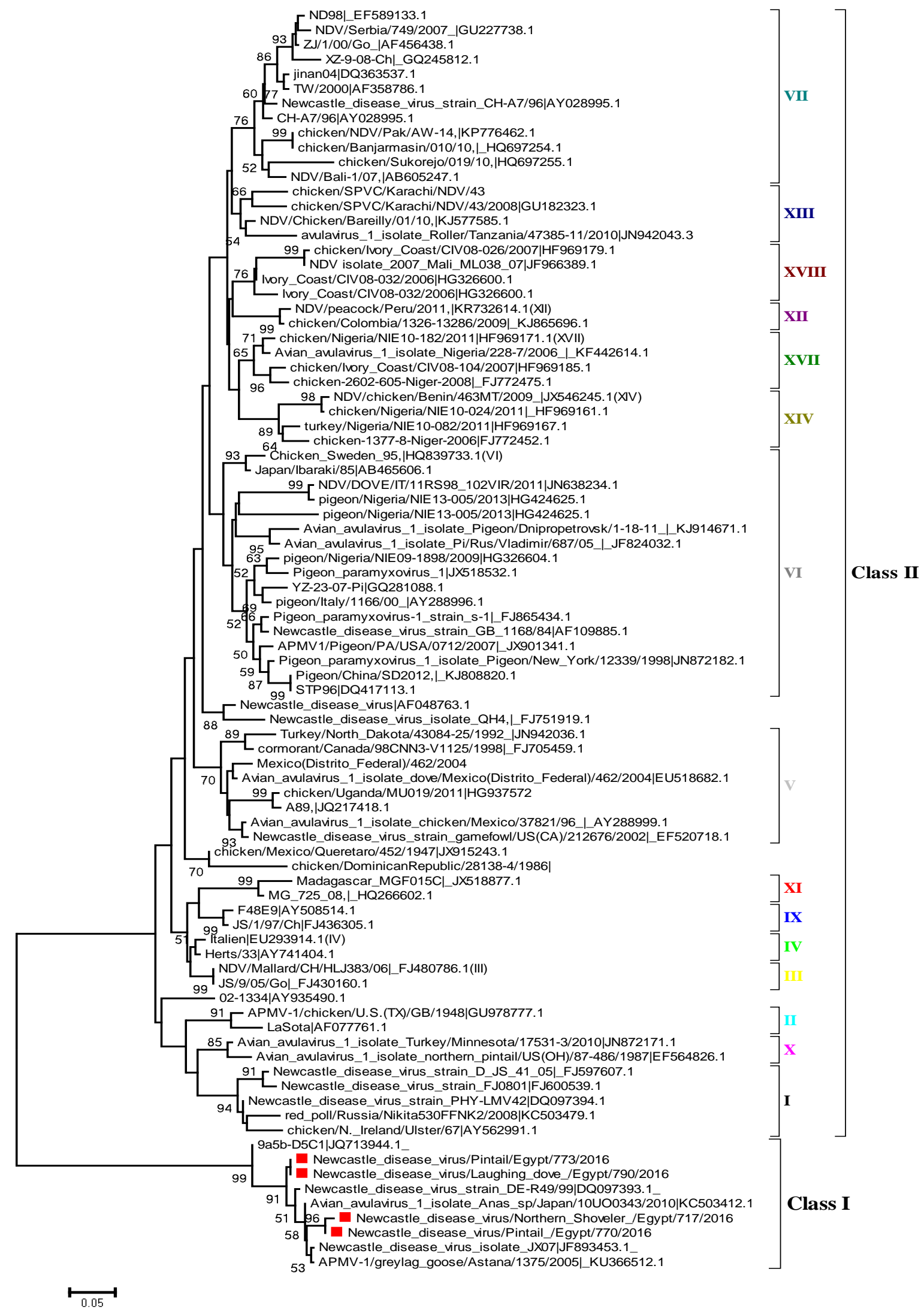

Figure 2. Neighbor-joining phylogenetic tree of Newcastle disease virus isolates based on F gene sequences. The wild bird isolates sequenced in this study are marked with red color. 

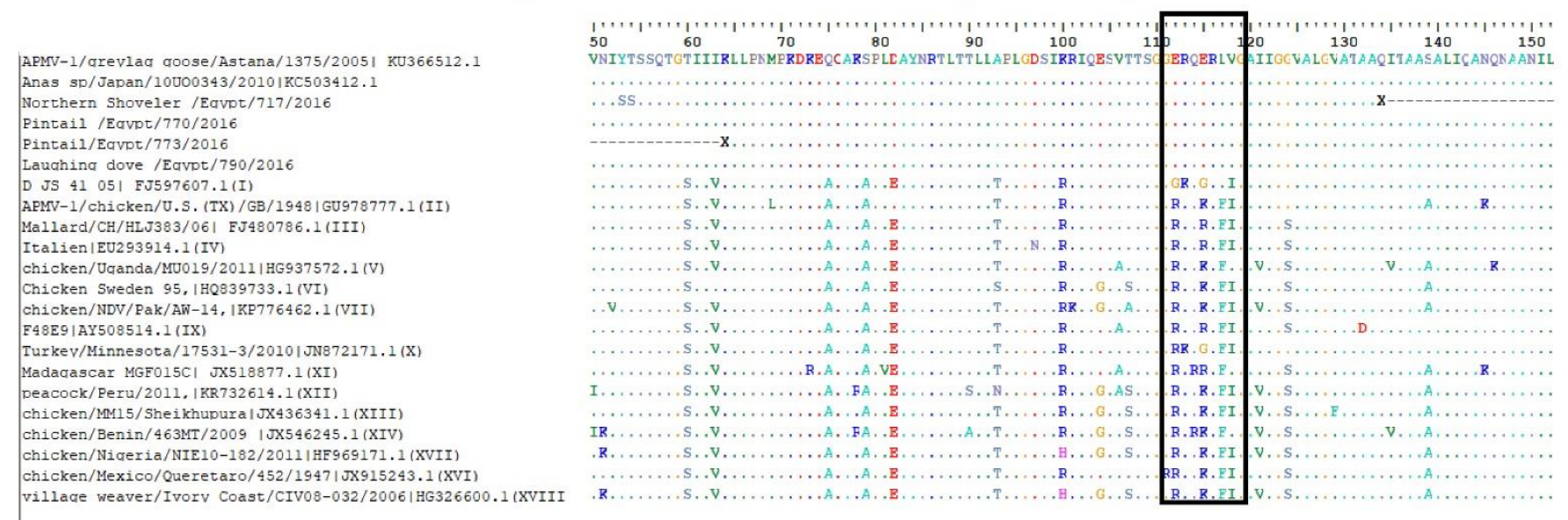

Figure 3. Alignment of the deduced amino acid sequences of the $\mathrm{F}$ gene of Newcastle disease viruses (NDV) isolated from wild birds in Egypt compared with class I and class II NDV strains. '?' indicates a site at which the amino acid residue is identical. The F protein cleavage site amino acid sequences of NDV isolates were labeled by a black rectangle.

\section{DECLARATIONS}

\section{Acknowledgments}

This work was funded by the Science and Technology Development Fund (STDF) in Egypt, under contract number 5175 .

\section{Authors' contributions}

All authors participated in the design of the study. Mohammed Hasan did all the experimental procedures. Mohammed Hasan and Ahmed Kandeil analyzed the obtained data. All authors participated in writing and reviewing the manuscript.

\section{Competing interests}

The authors declare no conflict of interest.

\section{REFERENCES}

Alexander DJ (2007). An overview of the epidemiology of avian influenza. Vaccine, 25(30): 5637-5644. Available at: http://www.ncbi.nlm.nih.gov/pubmed/17126960.

Alexander DJ, Campbell G, Manvell RJ, Collins MS, Parsons G, and McNulty MS (1992). Characterisation of an antigenically unusual virus responsible for two outbreaks of Newcastle disease in the Republic of Ireland in 1990. The Veterinary Record, 130(4): 65. Available at: http://www.ncbi.nlm.nih.gov/pubmed/1532467.

Collins MS, Bashiruddin JB and Alexander DJ (1993). Deduced amino acid sequences at the fusion protein cleavage site of Newcastle disease viruses showing variation in antigenicity and pathogenicity. Archives of Virology, 128 (3-4): 363-370. Available at: http://www.ncbi.nlm.nih.gov/pubmed/8435046.

Dimitrov KM, Ramey AM, Qiu X, Bahl J and Afonso CL (2016). Temporal, geographic, and host distribution of avian paramyxovirus 1 (Newcastle disease virus). Infection, Genetics and Evolution, 39: 22-34. Available

http://www.ncbi.nlm.nih.gov/pubmed/26792710

Dortmans JC, Koch G, Rottier PJ and Peeters BP (2011). Virulence of Newcastle disease virus: what is known so far?. Veterinary
Research, 42(1): 122. DOI: https://doi.org/10.1186/1297-9716-42$\underline{122}$

Fan S, Wang T, Gao X, Ying Y, Li, X, Li, Y and Xu Y (2015). Phylogenetic analysis of Newcastle disease viruses isolated from wild birds in the Poyang Lake region of China. Journal of Veterinary Medical Science, 14: 0080. Available at: http://www.ncbi.nlm.nih.gov/pubmed/25843743.

Huovilainen A, Ek-Kommonen C, Manvell R and Kinnunen L (2001). Phylogenetic analysis of avian paramyxovirus 1 strains isolated in Finland. Archives of Virology, 146(9): 1775-1785. Available at: http://www.ncbi.nlm.nih.gov/pubmed/11699962.

International Committee on Taxonomy of Viruses (ICTV) (2013). Virus taxonomy. Available at: https://talk.ictvonline.org/taxonomy/

Jindal N, Chander Y, Chockalingam AK, De Abin M, Redig PT and Goyal SM (2009). Phylogenetic analysis of Newcastle disease viruses isolated from waterfowl in the upper Midwest region of the United States. Virology Journal, 6(1): 191. Available at: http://www.ncbi.nlm.nih.gov/pubmed/19891788.

Kim LM, King DJ, Curry PE, Suarez DL, Swayne DE, Stallknecht DE and Afonso CL (2007). Phylogenetic diversity among lowvirulence Newcastle disease viruses from waterfowl and shorebirds and comparison of genotype distributions to those of poultry-origin isolates. Journal of Virology, 81(22): 12641-12653. Available at: http://www.ncbi.nlm.nih.gov/pubmed/17855536.

Mohamed MH, Kumar S, Paldurai A and Samal SK (2011). Sequence analysis of fusion protein gene of Newcastle disease virus isolated from outbreaks in Egypt during 2006. Virology Journal, 8(1): 237. Available at: http://www.ncbi.nlm.nih.gov/pubmed/21592379.

Mohamed MH, Kumar S, Paldurai A, Megahed MM, Ghanem IA, Lebdah MA and Samal SK (2009). Complete genome sequence of a virulent Newcastle disease virus isolated from an outbreak in chickens in Egypt. Virus Genes, 39(2): 234-237. Available at: http://www.ncbi.nlm.nih.gov/pubmed/19590944.

Pang Y, Wang H, Girshick T, Xie Z and Khan MI (2002). Development and application of a multiplex polymerase chain reaction for avian respiratory agents. Avian Diseases, 46(3): 691-699. Available at: http://www.ncbi.nlm.nih.gov/pubmed/12243534.

Saad AM, Samy A, Soliman MA, Arafa A, Zanaty A, Hassan MK and Hussein AH (2017). Genotypic and pathogenic characterization of genotype VII Newcastle disease viruses isolated from commercial farms in Egypt and evaluation of heterologous antibody responses. Archives of Virology, 162(7): 1985-1994. Available at: http://www.ncbi.nlm.nih.gov/pubmed/28343263. 
Shakal M, Maher M, Metwally AS, AbdelSabour MA, Madbbouly YM and Safwat G (2020). Molecular identification of a velogenic Newcastle disease virus strain isolated from Egypt. Journal of World's Poultry Research, 10 (2S): 195-202. Available at: http://jwpr.science-

line.com/attachments/article/55/JWPR\%2010(2S)\%20195202,\%202020.pdf.

Swayne DE and King DJ (2003). Avian influenza and Newcastle disease. Journal of the American Veterinary Medical Association, 222(11): 1534-1540.

Available

at: http://www.ncbi.nlm.nih.gov/pubmed/12784958.

Tong S, Chern SW, Li Y, Pallansch MA and Anderson LJ (2008). Sensitive and broadly reactive reverse transcription-PCR assays to detect novel paramyxoviruses. Journal of Clinical Microbiology, 46(8): $\quad 2652-2658 . \quad$ DOI: https://doi.org/10.1128/JCM.00192-08

Wang Y, Yu W, Huo N, Wang W, Guo Y, Wei Q and Xiao S (2017). Comprehensive analysis of amino acid sequence diversity at the $\mathrm{F}$ protein cleavage site of Newcastle disease virus in fusogenic activity. Public Library of Science One, 12(9): e0183923. Available at: http://www.ncbi.nlm.nih.gov/pubmed/28863165.

Xiao S, Paldurai A, Nayak B, Samuel A, Bharoto EE, Prajitno TY, Collins PL and Samal SK (2012). Complete genome sequences of Newcastle disease virus strains circulating in chicken populations of Indonesia. Journal of Virology, 86(10): 5969-5970. Available at: https://doi.org/10.1128/JVI.00546-12 